\title{
IoT System for Internet Connection Monitoring with Automatic Modem Reset
}

\author{
João W. S. Araujo \\ Computer Science Department \\ Federal Institute of Ceara, Brazil
}

\author{
João F. de O. Junior \\ Computer Science Department \\ Federal Institute of Ceara, Brazil
}

\author{
Sandro C. S. Jucá \\ Computer Science Department \\ Federal Institute of Ceara, Brazil
}

\begin{abstract}
This article aims to show a solution for people and companys who constantly face issues with internet signal loss. Therefore, taking this approching of internet connection failure as the case study and utilizing the NodeMCU, relay, libraries ESP8266Ping.h and Gsender.h, it was made a prototype so that the modem automatically stores the drop-down and the return time of connection. Thus with the fall and return times, these informations will be sent to an email to be used as control information.
\end{abstract}

\section{General Terms}

Computing, Embedded systems, Online monitoring

\section{Keywords}

Relay, ESP8266, Gsender, IoT

\section{INTRODUCTION}

The fast technological advancements of the last few years allowed computing to evolve, so that computing devices were reduced in size and at the same time optimized their processing capabilities. These technological advancements allow the development of more sophisticated and precise solutions to assist in a wide range of purposes, from equipment communication, organizational decision making, process automation, or even home automation [4].

Then, an area of technology has emerged that has the purpose of managing networked equipment. IoT (Internet of Things) equipment are devices with network access that can interconnect and communicate with each other [14].

This article aims to find an automatic solution for the constant falls of the Internet that happens in the homes of users or company's facilities who use wifi modem, storing the failure and return times for a better monitoring of the connection. In fact, it becomes a nuisance users having to get up and go to the location where is the modem to restart it. This article aims to create a prototype that stores idle network times and automatically reboots the modem.

\section{THEORETICAL FOUNDATION}

Microcontroller is a small computer (SoC - System On Chip) on a single integrated circuit which contains a processor core, memory and programmable input and output peripherals. The programming memory can be RAM, NOR flash or PROM which is often included in the chip. Microcontrollers are designed for embedded applications, in contrast to microprocessors used in personal computers or other general purpose applications [10].

NodeMCU was created shortly after the release of ESP8266. On December 30, 2013, the company Espressif began producing the ESP8266. The production of NodeMCU began on October 13, 2014, when Hong posted the first nodemcu-firmware file on GitHub. Two months later, the project expanded to include an open hardware platform when developer Huang R. published the gerber file of an ESP8266 board, calling it devkit 1.0 [3].

NTP stands for Network Time Protocol. It is the protocol that allows the synchronization of the clocks of the devices of a network like servers, workstations, routers and other equipment from reliable references of time [18].

A flexible long-term real-time monitoring system for PV plants developed at the University of Huddersfield, UK, can be found in [6]. The system monitors a weather station and a PV system connected to the grid that produces $1.98 \mathrm{kWp}$. The system is made around wired / wireless devices and it uses IoT to integrate monitoring of photovoltaic and environmental data. Different programming platforms were used in development such as LabVIEW, Arduino and Weather Link. Two communication links to monitor all data locally and remotely were used. Radio frequency modules, Bluetooth chip and Ethernet protection based on a static IP address are used to offer different monitoring options.

A computational platform was developed for real-time power flow models with the integration of intelligent measurement, real-time monitoring and an information management system developed at the National University of Colombia, Bogotá Campus [16]. With a capacity of $15 \mathrm{kWp}$ the communication used consists of a computer with a wireless network card that collects the meter data via WiFi. The meter is connected to the output of a GSM modem for data transmission via Ethernet and the computer is connected to the Internet to send data to the remote server. The real-time management system consists of three OSIsoft PI servers, two to collect and store a large volume of data and another to organize information in hierarchical structures for quick localization. Graphs of real-time behavior of voltage, current and power of the generated PV system are shown. 
Table 1. Comparison of various types of monitoring.

\begin{tabular}{|l|l|c|c|}
\hline Paper & Connection & Data transfer & System \\
\hline$[8]$ & Network & WI-FI and Ethernet & ADSL \\
\hline$[7]$ & Network & WI-FI and Ethernet & CDR \\
\hline$[2]$ & Network & WI-FI e Etherne & NULL \\
\hline$[13]$ & Network & Serial and USB & WEB \\
\hline$[9]$ & Undefined & Wireless Sensors & A cloud \\
\hline$[1]$ & Network & Wi-Fi, email and SMS & WEB \\
\hline$[17]$ & Network & WI-FI & WEB with arduino \\
\hline$[16]$ & Network & Wi-Fi, ethernet e GSM & A cloud \\
\hline
\end{tabular}

Monitoring the quality of a given service has become essential for users to have control over the service being provided. It is possible to find numerous works that deal with this topic (Table 1).

Day-to-day systems use Relays as a tool for triggering devices.

The device of remote activation of electric gates via cellular using microcontroller, this project integrates the Arduino UNO board, whose microcontroller is ATmega328, a board with SIM900 GSM module and a board with relay modules in a single prototype, performing user registration, adding new ones or removing existing registers, via text message sent by a system administrator - the first user to send an SMS to the prototype [11].

The proposal of a system capable of automating the drive of household equipment through the internet, on a free hardware platform. With HTML interface controlling and supervising a house with four common rooms, each room will have a compact fluorescent lamp. Ideally, the customer can be aware of each[15].

\section{METHODOLOGY}

The ESP8266Ping.h library was used. With this library, an ESP8266 can test the connection of the device with a remote machine and thus know if it can be accessed. The storage is done in a Boolean type, that is, it will be true if it is reachable, false if it can not be accessed. The library supports the host name too, just pass a string instead of the IP address. In addition, the function accepts a second integer parameter countque that specifies how many connection tests were performed [5].

The modem is connected to the prototype where the modem's male connector is connected to the female connector of the device, and the male connector of the device is connected to the socket. With the system on, the device at sixty seconds intervals tests the connection by performing three reachability tests for the different sites that are running 24 hours a day. After the connection tests two situations can happen. First, all three tests may have been terminated and the variable will hold true, which will cause another sixty seconds of waiting without restarting the modem, and after that, it will re-run the connection tests, starting the steps again. Second possibility is that one of the tests fails and the variable stores false causing the modem to turn off for ten seconds, after that time the modem is turned on and it waits another thirty seconds for the signal to be reestablished and again the device performs the tests. If the connection is established the return schedule will be stored and sent back with drop-off time for a pre-established email.

The textit Gsender.h library is used to send an email when the connection is established [12]. The steps that the system performs from drop to restart can be checked in a more illustrative way following the flowchart (Figure 1).

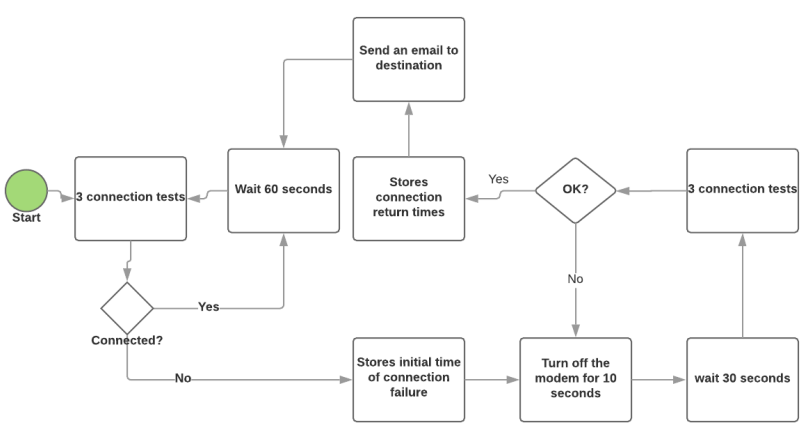

Fig. 1. Flow of system steps. [19]

In the first step, tests were done to detect the fall of the internet using only one LED that lit when it detected the fall. With only one GPIO pin (14) of the ESP8266 the circuit was prototyped along with the LED connected to the GPIO (14) that powered the LED when the internet dropped. Using the $3 \mathrm{G}$ internet routed from an ordinary cell phone, turning off and on the $\mathrm{Wi}-\mathrm{Fi}$ access point mode. The circuit consists of making the LED connected to the NodeMCU emit constant light for a period of 10 seconds when it detects the absence of the network to which it is connected.

The experiment was conducted in a residence with internet access provided by a broadband provider. A Wireless 300Mbps Router L1-RW333 was used for testing the network. We selected a four weeks period for further analysis to find out what days there is more connection idleness.

The destination email has to be changed to receive from untrusted sources. So, go into app settings and enable "Allow less secure apps".

\section{RESULTS}

The construction step was performed using the NodeMCU, modem, relay and a power cable where one end has a female plug connected and the other has a male plug. This cable is designed so that the power cord of the modem is not cut off and does not damage the equipment. The relay was used to enable the activation of a $220 \mathrm{~V}$ load through the GPIO14, using a voltage of $5 \mathrm{~V}$ applied to the relay. Thus, the coil will generate an electromagnetic field attracting the NF (normally closed) contact which is connected or vec to the (normally open) NO, thus closing the circuit, thus allowing the modem current to be interrupted and then switched on, restarting so the equipment. The circuit diagram is shown below Figure 2.

Figure 3 shows the NodeMCU (A), Relay module (B) of the assembled circuit on a circuit board.

Table 2 shows the time when the internet was idle for each day of the week in the selected period.

The initiative to create a prototype to monitor idle time proved to be quite effective in its results. The downtime from the moment the internet is disconnected and the return time of the connection were quite satisfactory. The time that the equipment is turned off is in accordance with the standard that is used by the vast majority of users (it is also the one recommended by the operators), that is, the time of ten seconds. 


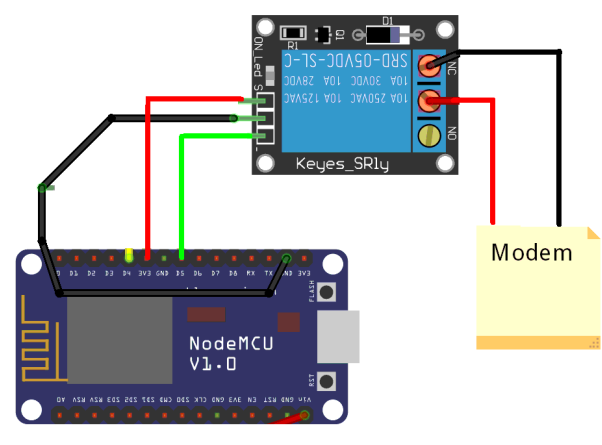

Fig. 2. Circuit diagram.

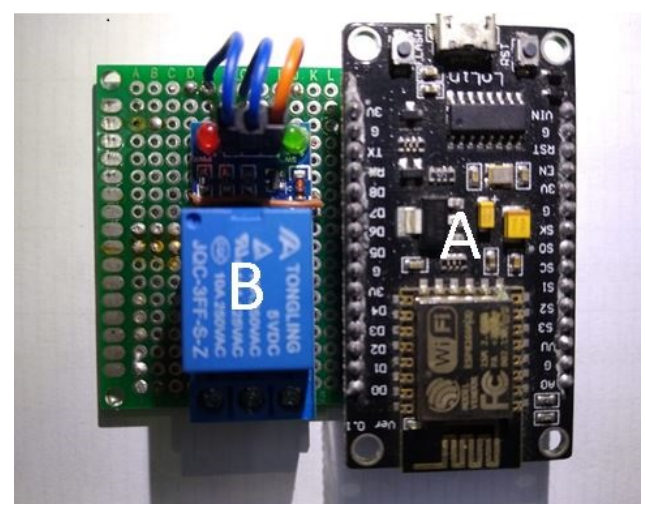

Fig. 3. Prototype Circuit

Table 2. Idle time per day.

\begin{tabular}{|l|l|c|c|c|}
\hline Days & First week & Second week & Third week & Fourth week \\
\hline Sunday & $00: 13: 24$ & $01: 34: 43$ & $00: 03: 12$ & $00: 21: 53$ \\
\hline Monday & $00: 09: 11$ & $00: 12: 07$ & $00: 04: 19$ & $00: 12: 46$ \\
\hline Tuesday & $00: 17: 55$ & $00: 05: 47$ & $00: 07: 04$ & $00: 11: 34$ \\
\hline Wednesday & $00: 40: 37$ & $00: 15: 59$ & $00: 18: 29$ & $00: 16: 12$ \\
\hline Thursday & $00: 18: 03$ & $00: 17: 21$ & $00: 09: 13$ & $00: 40: 35$ \\
\hline Friday & $00: 26: 40$ & $00: 23: 44$ & $00: 14: 22$ & $00: 15: 01$ \\
\hline Saturday & $02: 41: 20$ & $00: 10: 08$ & $00: 23: 48$ & $00: 09: 19$ \\
\hline
\end{tabular}

\section{CONCLUSIONS AND FUTURE DIRECTIONS}

Difficulties were found throughout the development of the prototype. When recording the code on the NodeMCU, the system detected only the first drop of the wifi, so the system did not loop. The solution found was quite simple, after the first drop the cable connected to the NodeMCU was disconnected and soon after connected, with this solution the system started to work perfectly.

Work can be evolved to a more effective solution. A log can be created to let the user know how many times the internet has fallen, which are the most common days without Internet access, the most common times of not having access to the Internet, thus generating greater control. These records can serve as evidence to the user regarding the carrier that provides the internet.

\section{REFERENCES}

[1] ETA Alves, DS Morim, MN Souza, and FF Rosário. Estudo de caso: Sistema para monitoramento de temperatura e umidade em farmácias e almoxarifados. In Congresso Brasileiro de Engenharia Biomédica, pages 1208-1211, 2014.

[2] GUILHERME P COLNAGO. Desenvolvimento e implementação de um sistema de monitoramento em tempo real da tensão da rede com acesso remoto. Master's thesis, Universidade Federal do Espírito Santo, 2009.

[3] Curcello. Apresentando o módulo esp8266. urlhttps://www.embarcados.com.br/modulo-esp8266/, 2015. Acesso em Setembro de 2018.

[4] Eduardo Germano da Silva, Tatiana Nilson dos Santos, Cristian Cleder Machado, Luis Augusto Dias Knob, and Anderson Luiz Fernandes Perez. Um sistema para automação residencial sensível ao contexto. Anais do Computer on the Beach, pages 051-060, 2015.

[5] Dancol90. Esp8266ping. urlhttps://github.com/dancol90/ESP8266Ping, 2015. Acesso em Setembro de 2018.

[6] Mahmoud Dhimish, Violeta Holmes, and Mark Dales. Gridconnected pv virtual instrument system (gcpv-vis) for detecting photovoltaic failure. In Environment Friendly Energies and Applications (EFEA), 2016 4th International Symposium on, pages 1-6. IEEE, 2016.

[7] Luciano Henrique Duque. Banda larga: Extração de parâmetros da qualidade do serviço a partir do cdr (call detail record). 2012.

[8] André Gruszynski. Mecanismo funcional escalável para contabilização de uso de serviços residenciais em rede de acesso em banda larga utilizando tecnologia adsl. 2008.

[9] Tao Hu, Minghui Zheng, Jianjun Tan, Li Zhu, and Wang Miao. Intelligent photovoltaic monitoring based on solar irradiance big data and wireless sensor networks. Ad Hoc Networks, 35:127-136, 2015.

[10] Morais Jose. O que É esp8266 - a família esp e o nodemcu. urlhttps://portal.vidadesilicio.com.br/o-queesp8266-nodemcu/, 2017. Acesso em Setembro de 2018.

[11] Gustavo Moura Fé MAIA. Acionamento remoto de portões elétricos via celular através de microcontrolador, 2012. Trabalho de Conclusão de Curso (Graduação em Engenharia da Computação)-Faculdade de Tecnologia e Ciências Sociais Aplicadas-FATECS, Centro Universitário de BrasíliaUniCEUB, Brasília DF, 2012.

[12] montotof. Gsender. urlhttps://github.com/montotof123/Esp826612, 2017. Acesso em Setembro de 2018.

[13] Genevieve C Ngo, Judd Kristian I Floriza, Christine May C Creayla, Felan Carlo C Garcia, and Erees Queen B Macabebe. Real-time energy monitoring system for grid-tied photovoltaic installations. In TENCON 2015-2015 IEEE Region 10 Conference, pages 1-4. IEEE, 2015.

[14] S Revell. Internet of things (iot) and machine to machine communications $(\mathrm{m} 2 \mathrm{~m})$ challenges and opportunities. Final paper, London, UK Google Scholar, 2013.

[15] Frankys Deylon ROSA, Maycon J Costa Mesquita, Wil Ribamar Mendes ALMEIDA, and Patricio Moreira de 
ARAUJO Filho. Controle e supervisão residencial utilizando a plataforma arduino. Acta Brazilian Science, pages 68-73, 2013.

[16] William Montaño Salamanca and Javier A Rosero García. Computing platform for power flow models in real time: Case study-real-time monitoring on a photovoltaic generation system and its integration into the load flow of universidad nacional de colombia power grid model. In Transmission \& Distribution Conference and Exposition-Latin America (PES T\&D-LA), 2016 IEEE PES, pages 1-8. IEEE, 2016.

[17] Natan Zaqeu Gaio Spricigo, Herculano Haymussi De Biasi, and Rosicler Felippi Puerari. Sistema de dosagem com controle e monitoramento iot. Seminário de Iniciação Científica, Seminário Integrado de Ensino, Pesquisa e Extensão e Mostra Universitária, 2017.

[18] Thiago. Ntp - network time protocol ou protocolo de tempo para redes. urlhttps://sempreupdate.com.br/ntp-networktime-protocol-ou-protocolo-de-tempo-para-redes/, 2018. Acesso em Setembro de 2018.

[19] Welton(a). Fluxograma dos passos do sistema. urlhttps://www.lucidchart.com/documents/edit/a7e8a500be3e-4b27-9931-2cbf7ff79981/0, 2018. Acesso em Setembro de 2018. 